\title{
Remediating childhood recollection: facilitating intermedial theatre based on lived-experience, recollection and remediation of digital video.
}

\author{
Author: Jem Kelly \\ Senior Lecturer in Performing Arts (Film, TV and Stage) \\ Buckinghamshire New University, High Wycombe, UK \\ Jem.kelly@bucks.ac.uk
}

\begin{abstract}
This paper reports on an intermedial pedagogy informed by Jacques Rancière's Ignorant Schoolmaster (1991). Two case studies interrogate the creative application of notions found in intermedial practice, hypersurface and palimpsest, discussing student agency as rigorous, innovative and research-led. The emerging status of pedagogy in higher education calls for 'teaching...to be identified with research activities in some direct way' (D'Andrea and Gosling 2005, 154). Through a descriptive analysis of two case studies I will show how my own intermedial research activity informs the teaching and learning on the BA Performing Arts (Film, TV and Stage) programme at Bucks New University.
\end{abstract}

Keywords: intermediality, palimpsest, hypersurface, memory, Station House Opera.

\section{Biography}

Jem Kelly is Creative Director of repeaterperformance a Brighton based company specialising in intermedial performance. His current research practice interrogates memory-themed sound-driven performance, seeking new ways to re-present and remediate mnemonic artefacts (photographs, sounds, videos) into performance. Since 2006 he has worked as dramaturge, performer and digital archivist with Station House Opera, leading a symposium in September 2014, The Spaces of Telematic Performance, which incorporated The Doors, a telematic performance linking spaces in Central School of Speech and Drama, London and Bucks New University, High Wycombe through multi-channel web streaming of video, and electro-mechanical interactive doors, in which he also performed. 


\section{Intermedial Praxis}

This paper reflects on intermedial praxis coupled with a teaching mode, inspired by aspects of Jacques Rancière's Ignorant Schoolmaster (1991), that requires a high level of self-direction and self-reflection in the student. The paper will focus on the reification of theory in two instances of student intermedial performance practice, the research, teaching and stimuli informing these, and concludes with a reflection on the practice assessed.

Intermediality is concept increasingly used across different discourses and for this reason requires definition and contextualisation in relation to the field of theatrical performance. Current debates around intermediality interrogate interactions and interrelations of digitally mediated forms and structures in performance, notably 'materiality (or ontology), mediality (or functionality) and modes of perception,' (Kattenbelt 2006, 27). These concerns also resonate with theories and practices of the early $\mathrm{C} 2 \mathrm{O}^{\text {th }}$ that used analogue technologies to raise similar concerns. For example, Sergei Eisenstein's theorization, The Montage Of Attractions proposes a version of intermediality based on analogue forms and the interaction of these elements of live performance: 'all the parts that constitute the apparatus of theatre' (Eisenstein 1923, 29). It is interesting to note, that Eisenstein's first theatrical direction staged in 1923, The Wise Man, also included the projection of his first film, Glumov's Diary (Taylor 1998, 3). One of Eisenstein's key objectives is to produce 'specific emotional shocks in the spectator', with the intention of revealing an 'ideological aspect of what is shown' (Eisenstein 1923, 29). Eisenstein intends to annihilate theatres of transparency and illusion, producing instead a hypermedial theatre that emphasizes the constructed-ness of performance whilst making the audience aware of underlying political and ideological issues. Eisenstein's shock tactic thereby foregrounds the affective potential of intermediality, an issue to which I will return as the student work examined is emotionally affective.

In 1967, Fluxus artist Dick Higgins uses the term 'intermedia' to blur differences and 'emphasize the dialectic between media', which he opposes to the Renaissance notion of medium purity proffered by contemporary critics, notably Clement Greenberg (Higgins 1967). Higgins' theory was reified in two ways, both through the explosion of combinatory performance works emanating from the Fluxus movement and their Happenings, but also institutionalising the concept through the introduction of intermedia degrees in US higher education from 1968 (Harren 2016). 
From a formal perspective, Higgins' dialectical intermediality brings about the attenuation of medium specificity and the diffusion of 'monomedia' through an affective interaction between and across monomedial forms (Schröter 2010, 107). Whilst it is possible for a specific medium - video, film, photography, the body, live action - to be identified, apprehended or sensed in intermedial performances, medium specificity is always troubled by the intervention, co-presence and coengagement of another medium. The concept of intermediality is, therefore, reified in hybrid forms we currently associate with poststructural, postmodern and postdramatic performance practices.

This hybridity is often compelling at a formal level, but to captivate and sustain student (and audience) engagement beyond the surface of audio-visual spectacle requires a compelling, impactful and meaningful thematic content. For this reason, whilst the technical aspects of intermediality are interrogated through instruction and more conventional modes of practical encounter, the content of students' work is stimulated to express the students' ideas, interests and subjective experiences - in the case studies by remediating childhood memory.

\section{Pedagogy + Intermediality}

Conventional pedagogical modes call for students to develop academic, information and digital literacies, and in practice-led, composite modes of study students are also required to engage in workshop-based, exploratory, creative learning. With intermedial practice, there is always an element of technical training required owing to particular combinations of media that students are unlikely to have encountered (e.g. Isadora, Modul8, Arduino). However, it is important to draw on students' experiences of the technologies they regularly use to gather information or communicate and get them to reflect on the underlying issues of technology in more general terms. Hot at the time of writing include social networking technologies Snapchat, Tinder, Vine and Periscope, but students also arrive with an inherent adeptness at how to frame subjects, including themselves, using photographic and video media in smart phones, thanks in part to the vogue of the selfie. This latter skill came in particularly useful in the work to be discussed as performers become the focus of and are framed by the video lens in performance.

Students are encouraged to reflect on the cultural contexts and ideological positions inherent in the technologies they use. Questions arising include: how do these technologies engage the user? What modes of encounter are specific to them? What is new, what is remediated? What do they contribute to our identity? What new paradigms of social engagement do they afford? What assumptions about the world 
do these new technologies challenge, or uphold? These questions can help students reflect on how to engage with and produce meaningful intermedial performance that is also culturally and critically relevant.

Following from Jacques Rancière's theorisation of intellectual equality set-out in The Ignorant Schoolmaster, Kurt Thumlert rightly considers students to be amateur experts, 'self-sufficient, high-tech cultural producers' whose skills and competencies challenge 'traditional boundaries between specialists and nonexperts.' (Thumlert 2015, 115) However, not all students are so adept in the use of technologies as Prensky's (2001) Digital Natives, Digital Immigrants debate once claimed. Current theorists contest the idea that the generation of millenials identified as digital natives possess any more 'sophisticated knowledge of and skills with information technologies' than their tutors (Bennett, Maton and Kervin 2008, 777). This demands a differentiated learning approach, with students organised into groups with a mix of expertise. Rancière's position that student and tutor have equal capacity / agency in the learning process is useful as it avoids the pedagogical convention that the tutor's knowledge is the 'object...to be reproduced', which can be limiting if not debilitating in the students' ability to produce impactful, innovative work (Thumlert 2015, 116). By taking account of student experience and starting from a position of equality, students are 'invited...to improvise in the gap between an expert role' and one that is 'imitable by anyone' (Thulert 2015, 116). This alleviates tensions often found in the development of intermedial performance based around technical competency, paving the way for creative, thematic and interrogatory approaches to be practised.

\section{Theoretical Concerns: Hypersurface and Palimpsest}

The field of intermedial performance has developed a lexicon populated with useful terms that can also seem abtuse examples of jargonese coined by and for experts. Students are given a gradual introduction to terminology, with each technical term from the discourses and ideas underpinning debates and informing practice in the field encountered in exploratory ways, rather than being defined exhaustively. This encourages students to find new meanings for the terms themselves through practical exploration. Teaching intermediality requires examination of 'the mutual relations between materiality, mediality and aesthetic convention of making and perceiving' (Kattenbelt 2008, 27). Two terms redolent with these mutual relations are hypersurface and palimpsest, with the former prevalent in the field of intermediality and the latter currently burgeoning in hypermedial performance and on-line gaming.

In Virtual Theatres, Gabriella Giannachi gives an interesting and extended 
account of the term hypersurface, with examples of praxis that are useful for undergraduate students and researchers alike. She defines the hypersurface in spatial and metaphorical terms as the location 'where the real and the virtual meet each other'. (Giannachi 2004, 95). Students may have experience of interactive webbased activities that allow users to control or interact with avatars to "create disembodied identities and discourses in cyberspace.' (Auslander 1997, 126) This represents one manifestation of the hypersurface found in web-based hypermedial forms. Hypermediacy,

...makes us aware of the medium or media and (in sometimes subtle and sometimes obvious ways) reminds us for our desire for immediacy.

(Bolter and Grusin 2000, 35)

Applying this to hypermedial performance, the spectator is typically made aware of the function of, for example, cameras, projectors and screens, even though they might desire, or prefer to sense the more 'neutral perceptual impression made in the process of notionally immediate transmission' associated with illusory theatrical forms (Darroch 2010, 141). Students interrogate and debate these terms in the light of contemporary theatre practice in the hypermedial works of The Wooster Group, Blast Theory, The Builder's Association and Station House Opera. Students test out their version of ideas through practice and consider the pros and cons of realising a hypermedial performance register in which the spectator is always aware of the role and function of the intermedia exchanges.

\section{Praxis and Research Into Teaching}

Robin Nelson calls for a practice as research pedagogy 'in which 'professional practice' and 'academic theory' are not separated', a teaching mode that 'involves an iterative, dialogic engagement of doing-thinking' (Nelson 2013, 18 -19). This section describes how such an approach might be developed as it involves teaching that is directly informed by my own research practice and the business of doing intermedial performance professionally. My practise as research experience - as performer / director with repeaterperformance, and as dramaturge / performer with Station House Opera - directly informs theoretical approaches to practice in my teaching. In March 2012 I contributed to a week of devising workshops with Station House Opera, a company pre-eminent in the field of telematic performance, led by Creative Director, Julian Maynard-Smith. The workshop explored methods of video overlay that would develop into a telematic performance, Dissolved (2014). The intermedial technique operates by allowing performers to synchronise their posture, gesture, movements and facial expressions so that they appear to occupy the same 
bodily and spatial co-ordinates with the projected video images of other, remotely located performers. This video overlay produces a composite screened image (See Fig.1).

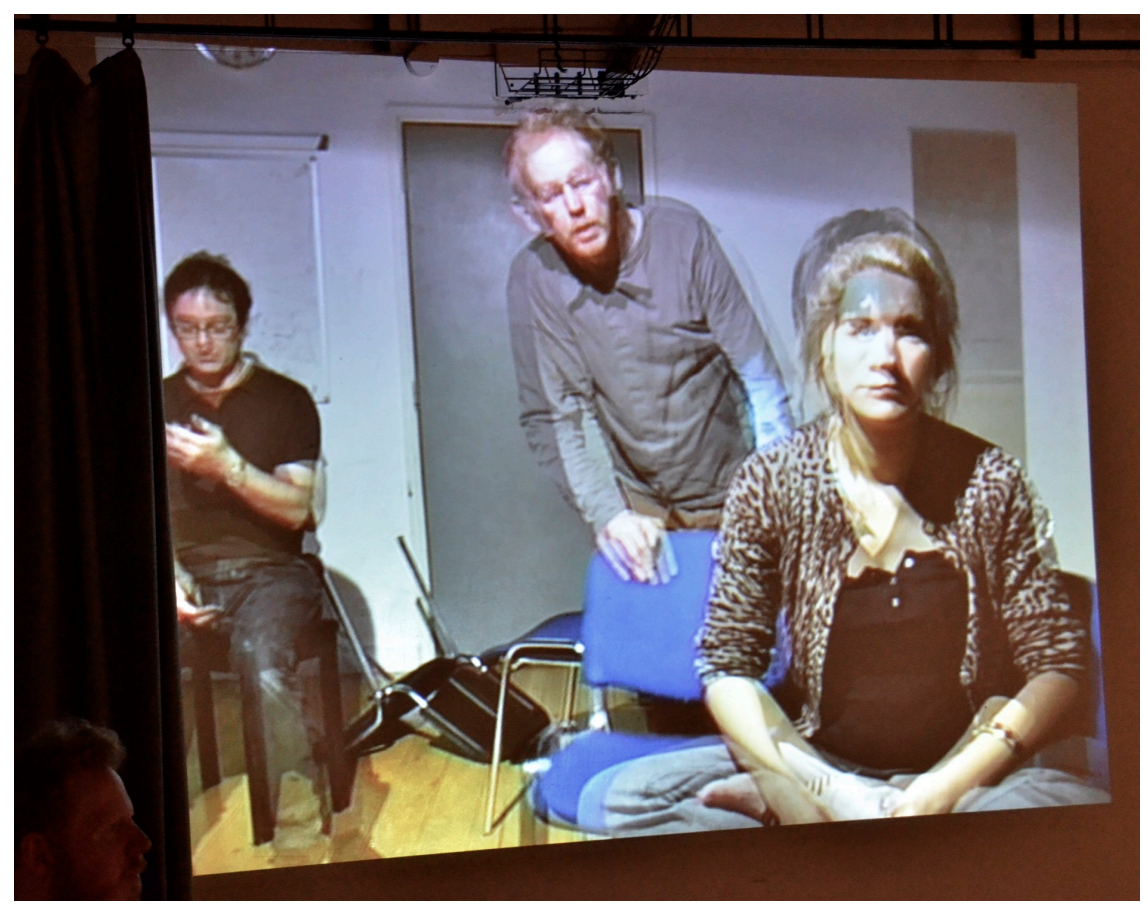

Figure 1. Station House Opera Workshop, 2012: Video overlay

This double virtual embodiment projected onto walls in the workshop proposes a new, other being comprising two discrete entities that cohabit the same virtual space. At this early stage of development, the workshop participants first record video clips of task-based actions, involving simple movement sequences. In Figure 1 (left), I had walked into the camera's field of view, paused, sat on a chair and then looked at my mobile phone. I had to match the sequence of movements as closely as possible with the performer who had previously done this on the recording. Two other performers struggle to bring their bodies into alignment with those of the prerecorded figures, with even the most basic of actions being extraordinarily difficult to align. A version of this workshop is used in my teaching, which alerts students to the practical possibilities for working with blended video images. However, students develop their own application, rather than blindly follow the specific workshop technique.

Following from this workshop at Level 5 , students are given a memorythemed stimulus designed to produce material that draws on individual and collective recollections. The rationale is that by drawing upon the students' own lived experiences, the false pedagogical dichotomy of tutor / student, expert / novice is 
inverted, troubled or annihilated through the representation of experiences and situations about which students are the owners. The stimulus is always negotiated with small groups of students (4-5 in number), so that individual members feel comfortable with the content, theme and process.

One group, for example, decided to use the technique of live video overlay encountered in the practical workshop, but which was also inspired by one of the students, Bradley Godbeer, performing as camera operator on my own practicebased research, Phantoms of the Aperture (2015). This performance uses a technique I refer to as palimpsest, in which a photograph of my father, projected onto a screen, has a live video of my face overlayed so that features match (Fig. 2). Bradley's role as videographer was to assist by framing my face with the camera so that it was brought into alignment with the projected photographic image. Bradley's pastime as an amateur photographer greatly helped the framing and a Roland V8 video mixer was used to control the amount and tone of visual blend between the two images.

An early form of palimpsest stems from the re-use of papyrus in which the first writing has been erased, but later re-emerges so that both written forms can be read simultaneously. In Phantoms of the Aperture (Fig.2), palimpsest operates as a literal overlay of images and a metaphorical overlay of time: the present mediation of live video performance is integrated with the past prompted by the photograph.

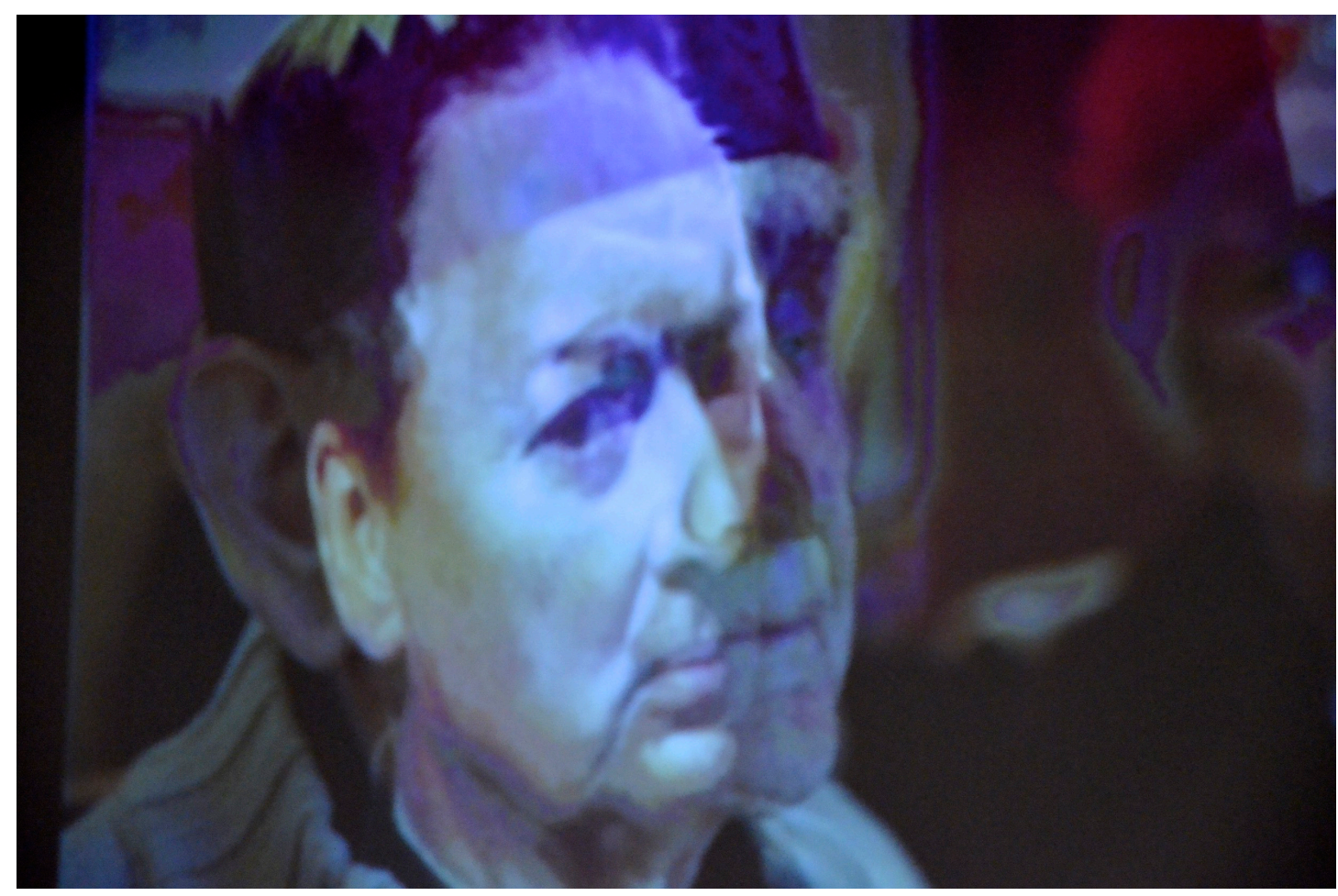

Figure 2 Phantoms of the Aperture (2015): visual palimpsest comprising live video and photographic images framed into a composite 
This technique of video and photographic blend, similar in effect to a cross dissolve in film, albeit a continuous one, appears not previously seen in theatrical performance, nor has its use been documented. However, Gabriela Cala-Lesina notes that Orlan's virtual Self-Hybridization series uses a form of palimpsest that 'manipulates photographs of her face with aspects of past civilizations, collapsing boundaries of culture and reality'. (Cala-Lesina 2011, 178) Exposure to Orlan's performance work entreats students to discover possibilities relating to their own religious and other cultural experiences in childhood, including personal appearance, alongside questions of gender identity and body-image. One aspect of Orlan's work is designed to remind spectators that the concept of natural beauty is a matter of history and fashion, a discursive construct, not a natural phenomenon.' (Auslander 1997, 128) This became a starting point for a student intermedial performance, Gardens Of Eden, which is our first case study. (Figure 3.)

\section{Case Study 1: Gardens Of Eden}

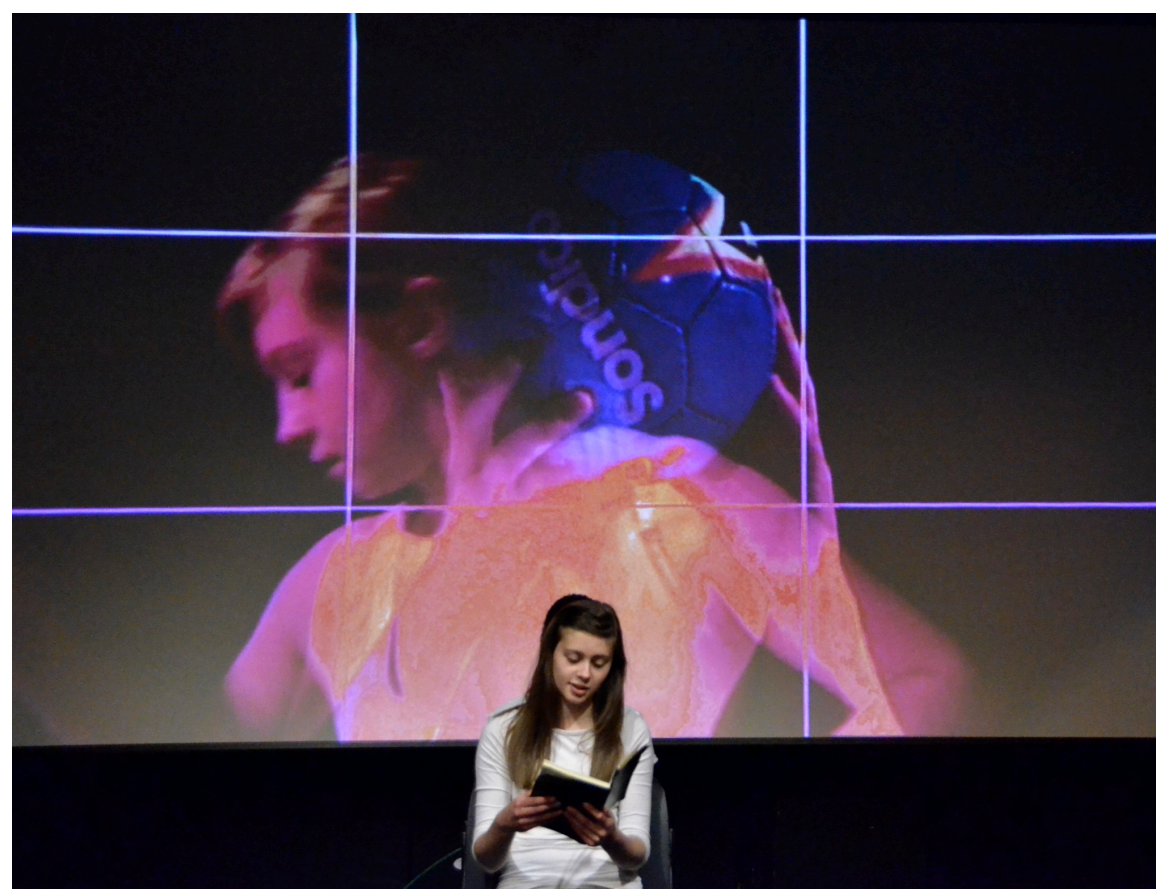

Figure 3 Gardens Of Eden - the Bible is re-gendered

Gardens Of Eden, is produced for a Level 5 (year 2) module, Site-responsive Performance and Intermediality taught at Bucks. In the second of two 15-week semesters, students develop theoretical knowledge, practical understanding and technical performance skills to devise and stage an instance of intermedial practice between $10-12$ minutes duration. Stimulus and technical training are negotiated 
and given, but the need for students to apply intermedial theory to their own practice is attained through critical inquiry and exploration in workshops. I adopt the role of 'facilitator', with the requirement that students are 'willing to be responsible for their own learning' (Joyce, Weil, and Showers 1992, 263). The performance is informed and shaped through intermedial praxis, but crucially draws on students' own experiences from childhood, which is the stimulus for content development. This practice is worth $30 \%$ of the total marks, with a critically informed evaluation of the performance a further $30 \%$. Both assignments meet the following Learning Outcomes:

- Work as an ensemble in the production of an intermedia performance, including an element of interactivity

- Theorise the role of performance within the social sphere as well as its relationship with sites and audiences (through practice).

- Record, evaluate and renegotiate practice and theory and their relationship to each other.

Gardens of Eden is an intermedial performance that combines video overlay and live action. In discussions with the group during the devising period, one student recollected attending bible class as a young girl and feeling ashamed that Eve was the first to commit sin, rather than Adam. From this, we discussed the possibility of re-gendering extracts from the Holy Bible as a means by which to foreground and redress the perceived gender bias. The performance was compelling as the realignment of gender exposed a phallocentric orientation of the biblical text in contradistinction to the gynocentric version offered by the performers: God makes Woman and takes a bone from her sleeping body to form Man. A further contrast is given in the video image, blending together a male and female face, producing an androgynous composite (Fig. 4).

The hypermediality of Gardens Of Eden functions as a visual reminder of gender construction as we see how the image is made. The video composite plays with the biblical narrative, for example when Eve's apple is blended with a leather football, which opens up the scope of the image to account for contemporary pursuits (Fig. 3). When the performers, whose videated images are live-streamed from the side of the stage, move out of alignment, then the spectator is able to separate out the objects and faces in the composite. In their written evaluation of Gardens Of Eden, students were able to reflect on the effects of the hypersurface created through the composite video image. They also evaluated the perceptual conditions of hypermediacy as one that: 
...privileges fragmentation, indeterminacy, and heterogeneity

and...emphasises process, or performance rather than finished art object

(Mitchell 1994, 8)

The troubling of gender through visual perception in the intermedial scene, generated by apprehending the equipment (cameras, video mixer), simultaneously produces and deconstructs an illusion of the blended faces into a virtual, third entity. It can be seen, therefore, that the pedagogical method of bringing together two discrete images to form a third is of particular relevance to the theme of the work.

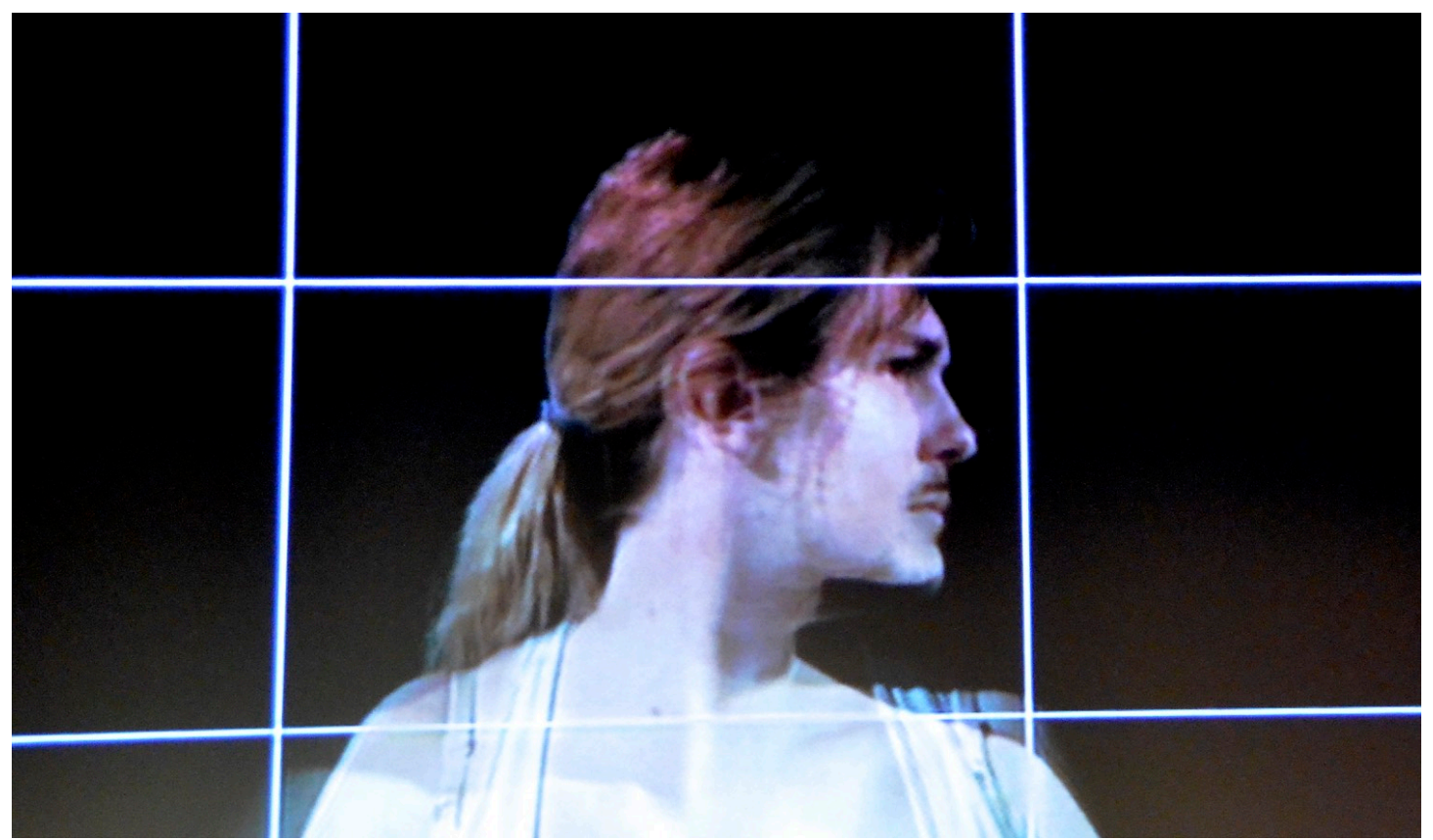

Figure 4 Gardens Of Eden - androgynous composite image blending fe/male

\section{Research Praxis and Collaborative Learning}

Undertaking intermedial practice as research can be difficult to achieve working alone, and in the case of interactive telematic performance impossible: assistants are required. The student-performer / assistant is afforded the opportunity to work with the researcher, sometimes collaboratively, and learning for both researcher and student can take place implicitly or explicitly through practical engagement and interaction. Such collaboration enables 'reflection on the kinds of knowledge practitioners bring to their workspaces' and subsequently for the student, 'may also provide the context for devising anew in a process of invention' (Nelson 2013, 40). 
Station House Opera, whose intermedial, telematic work often requires complex technical set-ups and improvisation from collaborators, staged two projects, Nowhere and The Doors, in which Bucks Performing Arts students were involved. In each performance, spaces in Royal Central School of Speech and Drama, London and Bucks New University, High Wycombe were linked in real-time using Internet networks to connect each location via live-streamed video.

For Nowhere (2013), I was dramaturge at Bucks, directing action following a set of site-responsive rules and overseeing technical operations. This gave my students the opportunity to participate, either as technical assistants or performers. The technical set-up for Nowhere is complex, but the performance draws on students' skills acquired in Acting for Camera, a module studied at Level 5 . Video from a rotating camera in each location is projected onto walls by two projectors in each space, orientated at 180 degrees apart. Sound follows image in each location: what the camera sees we also hear, which forms an audio blend of sound from both spaces. One student-performer, Jenny Wade, was tasked to play a guitar when she fell within view of a camera. (Figure 5) Whilst Jenny adhered to the rules, she was also a dynamic collaborator, improvising her movements, body position and guitar playing, learning what was possible within the constraints of the technical set-up.

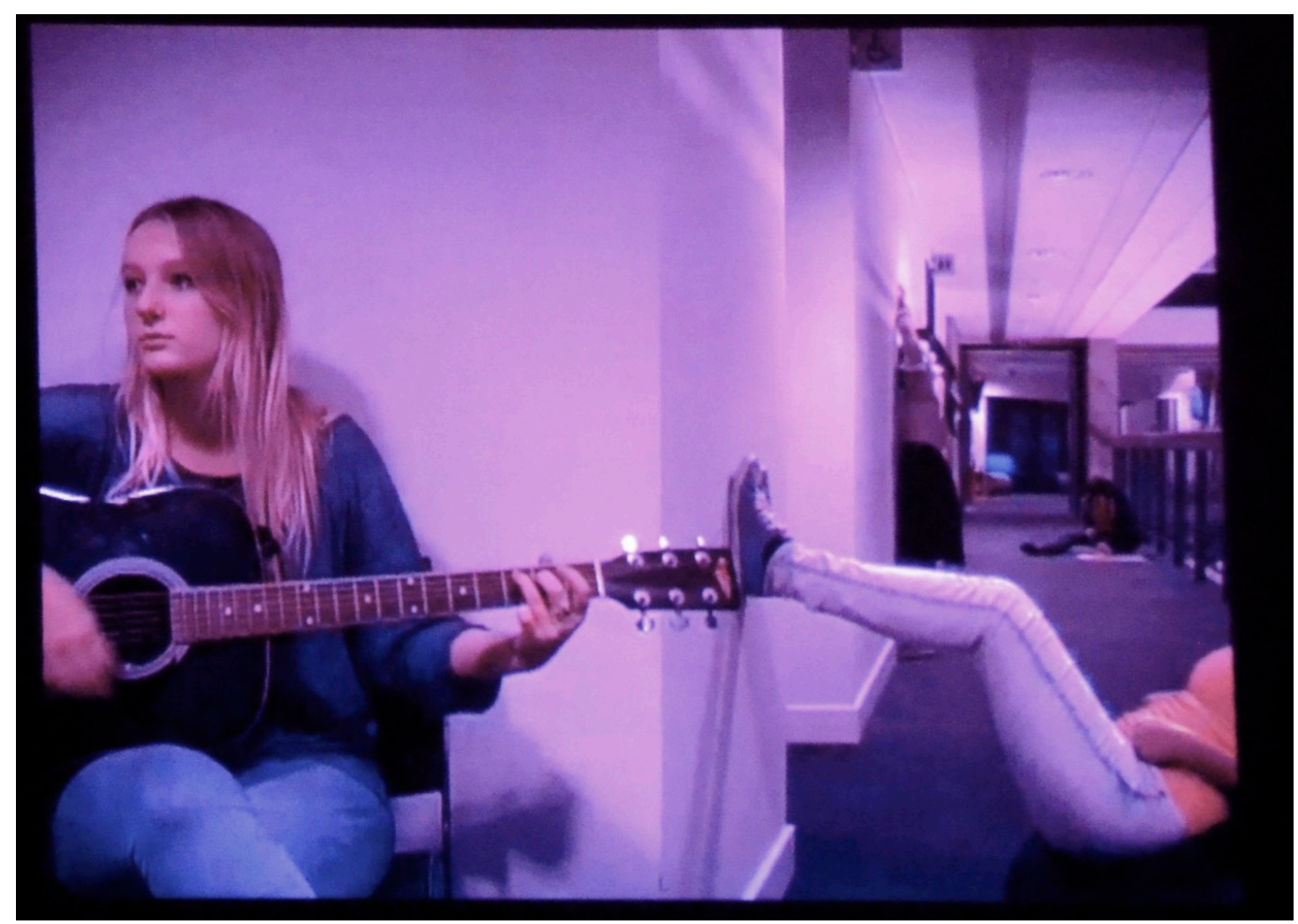

Figure 5 Nowhere (2013) Jenny Wade's performance is constrained by the camera, mounted on a motor, as it turns into her field of view. 
An aspect of collaborative learning is that the tutor / student role is replaced by a cooperative relation of mutual interest and discovery. Jenny was intrigued by the technical operations that produced a surreal, dream-like overlay of one surface (at Bucks) having the architectural features and figures inhabiting another space (at RCSSD) over-layed on top of it, producing a palimpsestic hypersurface where the virtual and actual collide. Both spaces could be seen simultaneously, providing an example of visual palimpsest demanding simultaneous audio / visual apprehension of two discrete places, only one of which could be recognised as the space actually inhabited by audience members. In Nowhere, it was difficult for performers to bear witness to their own roles and actions, as the spaces they occupied were outside that in which the images were projected. This intrigued Jenny and she challenged the prescribed role of performer routinely enacting a set of given behaviours, with one that was also self-determined.

A year later, after having participated in The Doors, a durational performance staged as part of The Spaces of Telematic Theatre symposium in September 2014, Jenny decided to pursue a practical dissertation that would draw on her experience. As with Nowhere, The Doors blended mises-en-scene from both locations, forming a palimpsest in which the performing figures are separated out (Figure 6).

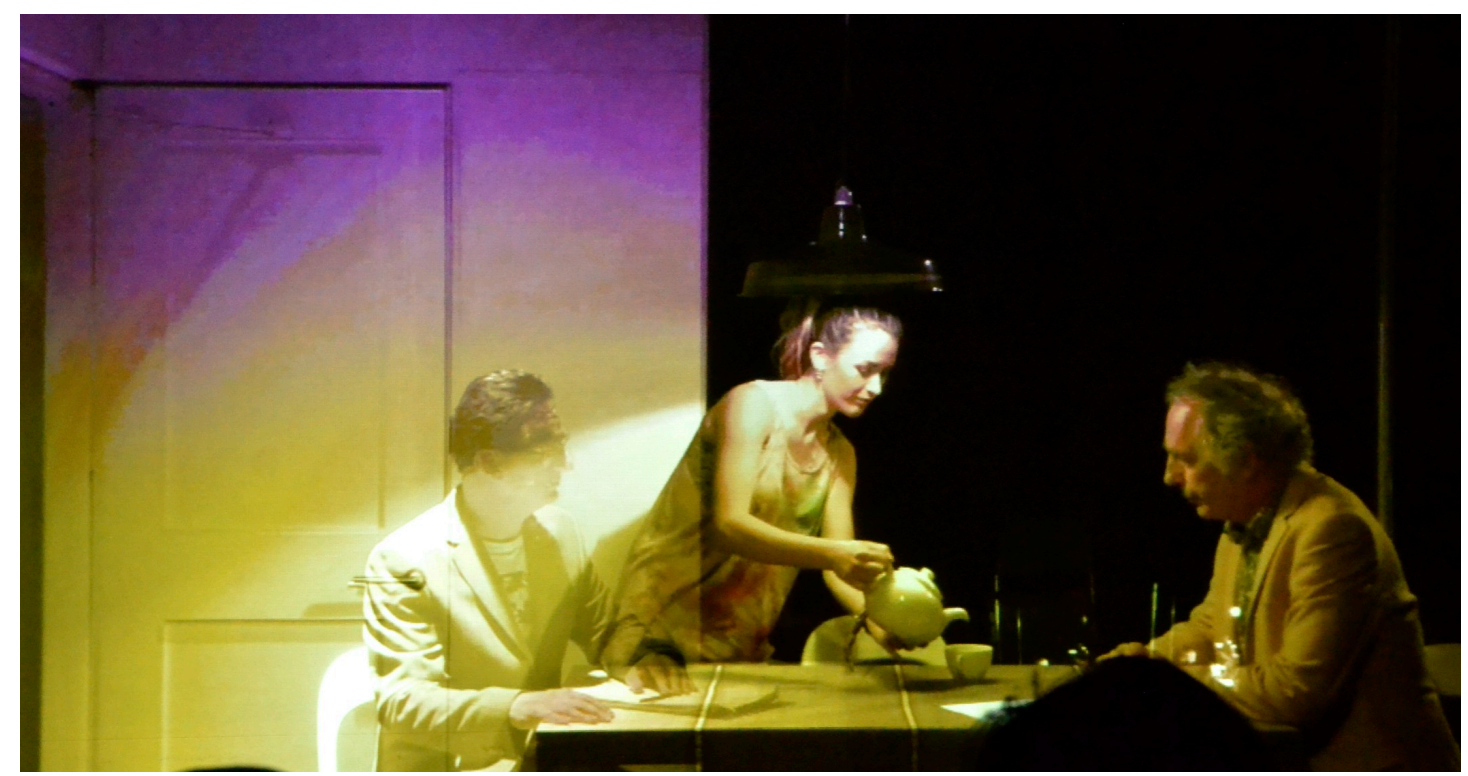

Figure 6 The Doors (2014) Performers in RCSSD and Bucks New Uni are blended into a composite image 


\section{Case Study 2: Together Again}

Together Again is a memory-themed, intermedial solo performance using video palimpsest to combine live video and playback video. This was a technical mode Jenny sought to develop in her own work, but she required guidance in applying the video overlay techniques to her childhood memories. In discussion, we revisited one of Giannachi's definitions of hypersurface, expressed as a 'hyper-sure-face, a space twice removed from the "face"'(Giannachi 2004, 95). This seemed to resonate with the fact that Jenny had no memories of her birth mother's face, except in a few photographs and a video clip taken when Jenny was a toddler. Jenny made a creative response to a theoretical perspective, riffing off the ideas raised in Giannachi's phrase. To prepare for the practical component, we engaged in a series of tutorials loosely following a Socratic, non-directive mode of question and answer.

Jem We discussed your idea of creating an 'impossible space', which grows from your experience as performer with Station House Opera and from your Level 5 Intermedia Project. Can I ask what you mean by the term, impossible space in the context of your performance?

Jenny Well, through the intermedial technology I have created a virtual scenario in which my present self appears in a video image with my deceased birth mother.

Jem What is impossible about the image, what aspects do you wish to foreground?

Jenny As a 20 year old, I appear as a ghost image, because of the superimposition lessening the contrast in the original image. I seem to appear, virtually, alongside my mother, whom I never knew. It is also impossible for my 18 month-old self to occupy the same space as my 20 year-old self, but the video overlay allows this.

Jem In creating this virtual space, it seems to me that you wish to come closer to your mother in a way that was or is not possible. So, how has the intermedial technology influenced / made possible this coming together? Jenny The superimposition specifically, because finding the video depicting myself as a toddler with my mother was a revelation as I had no memory of that encounter beyond the video footage.

Jem So, your ability to represent your current self as a live videated presence working in actual space alongside a projected composite video image with your mother fulfils a desire of sorts to meet with her? Why a performance, and not just a film? 
Jenny The performance is live and the audience is co-present. I want them to see me reaching out and seeming to touch, whilst at the same time knowing this is impossible.

Jem I see. So, your superimposed image, produced by mixing a live video feed of your body in the theatre, offers a co-presence of the audience that in some way validates, or charges and enlivens the virtual encounter with your mother? Jenny Yes, I want to bring them (the audience) closer to my past in my presence with them. I feel a live performance equips me better to do this, rather than just with a film, which is a montage of past images.

Jem OK. When you have identified the duration of the video footage you wish to use, we can discuss how you are going to relate the live body to the images. We also need to work together in the performance space to develop the technical set-up.

This transcript is indicative of the kind of nondirective questioning that took place in numerous meetings undertaken during the devising period, prior to staging Together Again. It also served to assist Jenny in explaining how key ideas informed her thinking, which would later be evaluated and analysed in her written component to the practical dissertation. Whilst Jenny had a clear idea of the techniques she wished to use, based on her past experience collaborating with me on research projects, the final format was a matter for her personal exploration and experiment, with my intervening only if there was an issue she could not overcome alone.

The performance, Together Again, remediates video footage taken by Jenny's father, a keen amateur videographer, that is organised into looped sections representing different times in her childhood. Jenny's live figure, her videated diary entries (written aged $7-13$ ), objects and photographs are variously inserted into the video loops taken by her father. The performance was compelling as the intermedial exchanges between live and playback video enabled the autobiographical material to show images of every family member, except her father. Additional poignancy was attained, as only through the family archive was the performance realisable, with her absent father being represented by his viewpoint, his perspective and his first-person vision. Jenny's live interventions with playback video present the viewer with a hypermedial form in which the image of the older Jenny reaching out and touching her deceased mother is exposed to be an impossible illusion. (Figure 7) And yet it does something uncanny in bringing mother and daughter together again, virtually producing the kind of 'emotional shock' Eisenstein called for in his Montage of Attractions (Eisenstein 1923, 29). 


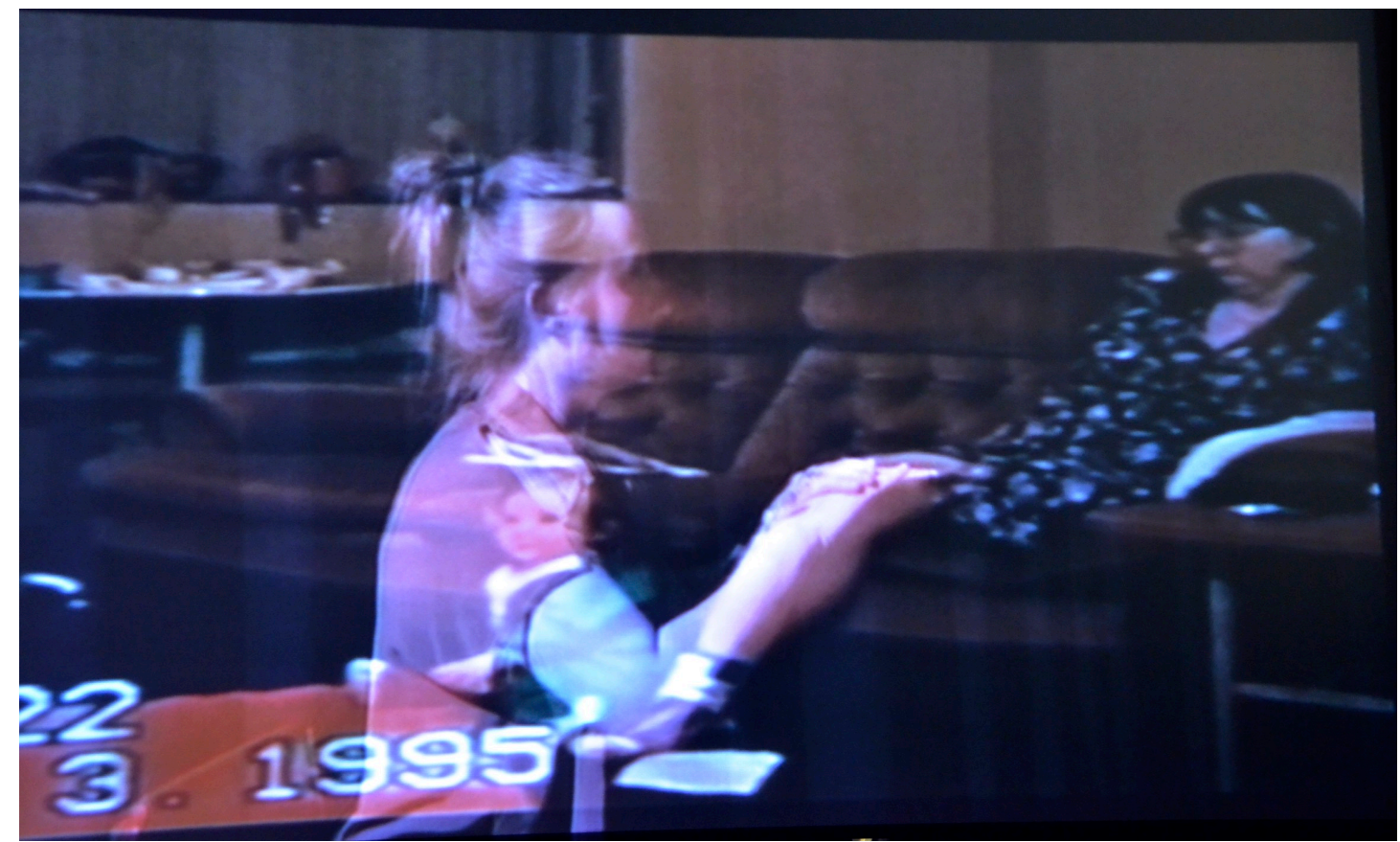

Figure 7 Together Again - Jenny's virtually present figure reaches out to touch her birth mother, whilst the figure of herself as a toddler runs in a circle.

\section{Conclusion}

In this report I have attempted to show ways in which a pedagogy of intermediality might depend on technical training and theoretical inquiry, but one in which the student / facilitator encounters challenge, erode or erase conventional pedagogical power binaries, such as knowledge / ignorance, expert / non-expert, professional / amateur. I have shown that theoretical concerns pertinent to the field of intermediality, notably hypersurface, palimpsest and hypermediality, can be grappled with and re-defined by students themselves through practice-led research performance. Whilst it is not always possible to involve students in practice-based research, I have demonstrated that students make excellent research collaborators and will develop personal insights to praxis that can inspire them to make new and innovative work. To paraphrase Martin Heidegger, it is always worth bearing in mind when teaching intermediality that the essence of technology is nothing technological. I have tried to show that by drawing on the students' own personal recollections and lived experiences, the content of intermedial performance can be just as impactful as the exchanges and interrelationships between the media used, with both forms and content producing thought provoking and emotionally affective experiences that cohere in their reception. 


\section{References}

Auslander, Philip. 1997. From Acting to Performance - essays in modernism and postmodernism. London: Routledge

Bennett, S. Maton, K. \& Kervin, L. 'The Digital Natives Debate: a critical review of the evidence'. British Journal of Educational Technology, 39 (5), 775-786.

Bolter, Jay David \& Richard Grusin. 2000 Remediation - Understanding New Media, Michigan: MIT

Cala-Lesina, Gabriela. 2011. Orlan's Self-Hybridizations - Collective Utopia or Twenty-First-Century Primitivism? in Third Text, Vol. 25, Issue 2, March, 2011.

D'Andrea, Vaneeta. and Gosling, David. 2005. Improving Teaching and Learning in Higher Education - A Whole Institution Approach. New York: SRHE

Darroch, Michael. 2010. Materiality in Mapping Intermediality in Performance, Eds. Bay-Cheng, S, Kattenbelt, C, Lavender, A \& Nelson, R 141 Amsterdam: Amsterdam University Press

Giannachi, Gabriela 2004. Virtual Theatres - an introduction. London: Routledge

Harren, Natalie. 2016 The Crux of Fluxus, Available at: http://www.walkerart.org/collections/publications/art-expanded/crux-of-fluxus/ Accessed: 07 January 2016, 10.42am

Higgins, Dick, 1967 Statement on Intermedia, Published in: Wolf Vostell (ed.): Décoll/age (décollage) *6, Typos Verlag, Frankfurt - Something Else Press, New York, July 1967 Available at: http://www.artpool.hu/Fluxus/Higgins/intermedia2.html Accessed: 04 January 2016, 09.49am

Joyce, Bruce. Weil, Marsha and Showers, Beverly. 1992. Models Of Teaching. Masachussetts: Allyn \& Bacon.

Kattenbelt, Chiel 2008 Intermediality in Theatre and Performance: Definitions, Perceptions and Medial Relationships, in Culture, Language And Representation Vol VI. 2008, pp. 19-29

Kattenbelt, Chiel 2010 'Portal: Performativity and Corporeal Literacy', in Eds. BayCheng, S, Kattenbelt, C., Lavender, A \& Nelson, R. Mapping Intermediality in Performance, (Amsterdam: Amsterdam University Press)

Michell, William, J. 1994 The Reconfigured Eye: Visual Truth in the PostPhotographic Era, Cambridge: MIT Press.

Nelson, Robin 2013. Practice As Research In The Arts - Principles, protocols, Pedagogies, Resistances London: Palgrave McMillan.

Schröter, Jens. 2010. The Politics of Intermediality in Film and Media Studies, ACTA Univ. Sapientiae, 2 (2010) 107-124

Prenksy, M. 2001. Digital Natives, Digital Immigrants. On the Horizon, MCB University Press, Vol. 9 No. 5, 1-6. 
Taylor, Rchard. Ed. Trans. 1998 The Eisenstein Reader, London: BFI

Thumlert, Kurt. 2015. Affordances of Equality: Rancière, Emerging Media, and the New Amateur in Studies in Art Education: A Journal Of Issues and Research 56 (2), $114-126$

Photography

All photographs courtesy of Jem Kelly.

All rights to use photographs in this publication granted by Jem Kelly. 